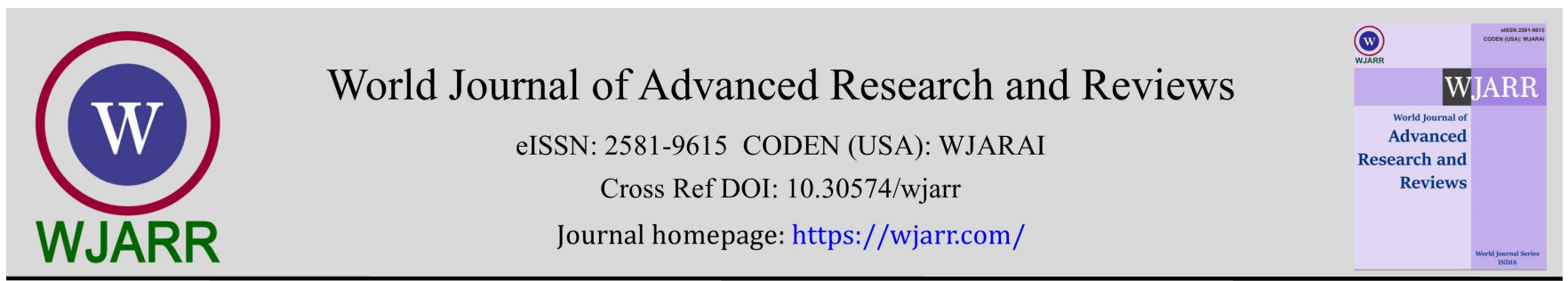

(RESEARCH ARTiClE)

Check for updates

\title{
Toxicological evaluation of a Nigeria-made polyherbal product on selected reproductive functions in adult male Wistar rats
}

Oluwaseyi Adegoke Adetunji 1, *, Oluwafunmilola Christiana Adetunji 1, Grace Aimalohi Agbebaku-Izobo 1, Gogonte Hezekiah Amah 1, Opeyemi Adebola Adetunji ${ }^{2}$, Adeola Mariam Sonuga ${ }^{1}$ and Babafemi Tosin Ogunbiyi ${ }^{1}$ and Modupe Olusola Adetayo ${ }^{1}$

1 Department of Biochemistry, School of Basic Medical Sciences, Babcock University, Ilishan-Remo, Ogun State, Nigeria.
${ }^{2}$ Department of Anatomy, School of Basic Medical Sciences, Babcock University, Ogun State, Nigeria.

World Journal of Advanced Research and Reviews, 2021,11(03), 001-008

Publication history: Received on 25 July 2021; revised on 28 August 2021; accepted on 30 August 2021

Article DOI: https://doi.org/10.30574/wjarr.2021.11.3.0410

\begin{abstract}
Ruzu bitters black for men (RBBM) is a polyherbal product widely used amongst men in Nigeria to enhance libido, rejuvenate male organs and to manage erectile dysfunctions, prostate anomalies, weak erection, and premature ejaculation. This study was carried out to investigate the toxicological effect from the use of herbal product. Acute toxicity test of RBBM on rats was carried out in two phases; $10 \mathrm{mg} / \mathrm{kg}, 100 \mathrm{mg} / \mathrm{kg}$ and $1000 \mathrm{mg} / \mathrm{kg}$ for phase I and $1600 \mathrm{mg} / \mathrm{kg}, 2900 \mathrm{mg} / \mathrm{kg}$ and $5000 \mathrm{mg} / \mathrm{kg}$ for phase II, were administered respectively. For sub-acute toxicity, two groups of 5 animals each received RBBM $(0.87 \mathrm{mg} / \mathrm{kg}$ and $1.17 \mathrm{mg} / \mathrm{kg}$ respectively $)$ and a third group received water orally for 28 days. The study analyzed the median lethal dosage, and sperm morphology, sperm motility, sperm count, sperm viability and histology of the testes as indices for sub-acute toxicity. No death was recorded for the acute and sub-acute studies but there was a moderate physical sign of toxicity. In the sub-acute toxicity study, there was a significant increase $(\mathrm{p}<0.05)$ in testicular weight of Group 1 animals. Also, sperm count, and sperm motility increases significantly $(\mathrm{p}<0.05)$ while there was a decrease in multiple tail sperm across the test groups. RBBM is not toxic to sperm morphology and causes no death at $5000 \mathrm{mg} / \mathrm{kg}$ in male albino Wistar rats.
\end{abstract}

Keywords: Ruzu bitters; Acute toxicity; Sub-acute toxicity; Polyherbal products; Sperm parameters

\section{Introduction}

Herbal medicine has been defined by World Health Organization (WHO) as refined authorized medicinal products that contain effective ingredients from aerial or underground parts of plants including fresh juices, essential oils, resins, gums, fixed oils, and dry powders of herbs leaves, bark, roots, rhizomes, or other plant parts which may be fragmented or powdered or combined in the crude state or as plant preparations [1]. In Nigeria as in other unindustrialized countries, herbal medicine contributes to the management of more than $80 \%$ of rural populace health challenges [2]. Herbal medicines are often polyherbal in composition, prepared from combining mixtures of many plant parts gotten from various plant species and families and may contain multiple bioactive components that could be difficult to characterize [2]. These polyherbal products are administered for extended period of time with no regulated dosage to monitor and consider toxic effects that might result from such prolonged usage. It is delusive that herbal remedy, being natural, may lack adverse and toxic effects, as it could be contaminated with microbes, their metabolites, and foreign materials such as heavy metals, and pesticide residues [3]. Contaminants present in herbal therapeutics preparations may elicit deleterious health effect upon administration of the preparations [4].

\footnotetext{
* Corresponding author: Oluwaseyi Adegoke Adetunji; E-mail: adetunjiol@babcock.edu.ng

Department of Biochemistry, School of Basic Medical Sciences, Babcock University, Ilishan-Remo, Ogun State, Nigeria. 
The increased male reproductive system problem has led to the use of several polyherbal products in Nigerian for case management [5]. The polyherbal products are not well regulated by the stipulated agencies in Nigeria and in many other low-income countries, making herbal products to be readily accessible [4]. Several investigations have shown risk of male infertility from the use of herbal remedies among Nigerian men [5]. Ruzu bitters black for men (RBBM) is composed of Uvaria Charmae, Curculigo Pilosa and Colocynthis Citrullus (collectively termed Ruzu herbal bitters) and other substances with aphrodisiac, rejuvenating and erectile dysfunction management potencies. This polyherbal product has claims for being able to enhance libido, rejuvenate male organs, correct erectile dysfunctions, and effectively manage prostate related cases, weak erection and premature ejaculation. Ruzu bitters black for men is used as a rejuvenation herbal mix for male organs and can be used just in time for mutual sexual satisfaction [6].

There has been no report on the acute and sub-acute toxicity that can result from overdose or prolong use of RBBM. In this study, some of the therapeutic (increased sperm count and viability) claims as well as the acute and sub-acute toxicity of RBBM were investigated. The goal of this study is to help consumers of this product have a better knowledge of the drug toxicological potential and a possible recommended consumable dose.

\section{Material and methods}

\subsection{Material collection}

\subsubsection{Collection of polyherbal product}

One pack of RBBM with NAFDAC registration number A7-1102L (manufactured by Ruzu Herbal Products and Services Ltd, Lagos, Nigeria) was purchased from a proprietary pharmaceutical outlet in Lagos, Nigeria.

\subsubsection{Animal housing and handling}

Sixteen adult male albino Wistar rats (120 to $180 \mathrm{~g}$ ) were obtained from the animal house of the Department of Biochemistry at Babcock University. The rats were housed under standard animal house research condition, fed on standard laboratory diet, and given water ad libitum. The rats acclimatized for seven days before the test commenced. All experimental protocols were carried out in compliance with regulatory guidelines and ethical certification was obtained from Babcock University Health Research Ethics Committee (BUHREC).

\subsubsection{Dose calculation}

The different doses selected for the toxicity study were chosen based on the dosage information published on the leaflet enclosed in RBBM pack ( 2 capsule per day). The dose for each group of subjects was calculated based on their kilogram body weights $(\mathrm{kg} / \mathrm{bw})$.

\subsection{Acute toxicity study (median lethal dose (ld50) determination)}

The acute toxicity study was conducted in two phases according to the modified method described by Lorke D [6].

\subsubsection{Animal grouping}

The study was conducted using a total of thirty-two (32) animals.

\subsubsection{Phase one}

The rats were divided into four groups of three animals each. Groups 1, 2 and 3 animals were given single dose of 10, 100 , and $1000 \mathrm{mg} / \mathrm{kg}$ RBBM orally respectively. Group 4 (control) received distilled water only. All animals were observed for signs of toxicity and possible deaths for $24 \mathrm{~h}, 72 \mathrm{~h}$, and 2 weeks.

\subsubsection{Phase two}

The rats were grouped into four. Group 1, 2, 3 animals received 1600, 2900 and $5000 \mathrm{mg} / \mathrm{kg}$ respectively, while group 4 (control) received distilled water only. The rats were fasted overnight prior to administration of the RBBM. They were equally monitored as in phase one for toxicity signs.

\subsection{Sub-acute toxicity study}

Sub-acute toxicity study was evaluated using the method described by Otimenyin et al, [7]. 


\subsubsection{Animal grouping}

Two groups of five animals each (group 1 and 2) received RBBM orally daily at a prescribed dosage of $500 \mathrm{mg}$ and 1000 mg per kilogram body weight (kg.bw) respectively for 28 days. Group 3 (control) was given distilled water daily for 28 days. The body weights of the rats were monitored during the period of administration. After 28 days, animals were allowed to fast overnight before being anaesthetized with diethyl ether. The animals were sacrificed, and semen and testis were harvested, weighed and preserved in $10 \%$ formalin for needful assays.

\subsection{Seminal analysis}

\subsubsection{Collection of semen}

The testicles and epididymis were exposed through a lower abdominal incision. The left caudal of epididymis was excised from the body of the testes. Sperm cells from the caudal were released into a petri dish containing normal saline to liquefy and migrate all spermatozoa from the epididymal tissue to the fluid $[8,9]$. This was done to evaluate sperm count, sperm morphology, and sperm motility.

\subsubsection{Sperm morphology}

To examine the sperm morphology, a drop of the sperm suspension was placed on a glass slide and a smear was prepared for microscopy. The smear was fixed in ethanol for $1 \mathrm{~h}$, stained with haematoxylin and eosin, washed, dried, and examined with a light microscope at a magnification of $\times 100$. Spermatozoa were counted and the percentage of abnormal sperm determined. Morphologic abnormalities of spermatozoa were categorized as,

- Head defect, including large, small, amorphous, and vacuolated, double heads or any combination of these.

- Tail defects, including absence of tail, short, multiple, hairpin, irregular width, or coiled tails, tails with terminal droplets, or any combination of these.

\subsubsection{Sperm Motility}

Cell motility was recorded and evaluated immediately after tissue isolation. A drop of sperm cells was placed on a glass slide, covered with slip and then examined under a light microscope (X400). Sperm cells that did not move at all were considered immotile while those that displayed some movements were considered to be motile. The percentage sperm motility was calculated using the number of live sperm divided by the total number of sperm cells.

\subsubsection{Sperm count}

The concentration and total count of spermatozoa was estimated using a Neubauer haemocytometer. A total of $10 \mathrm{ml}$ of the sample was withdrawn with a micro-pipette and delivered onto the edges of Neubauer chamber of haemocytometer. Both chambers of haemocytometer were scored, and the average count was calculated. The count was done under a light microscope at $\mathrm{x} 400$ magnifications and expressed as $\times 10^{6} / \mathrm{ml}$.

\subsubsection{Sperm Viability}

Sperm viability was immediately assessed and recorded after tissue isolation. One drop of semen was mixed with two drops of $1 \%$ of eosin followed by three drops of $10 \%$ nigrosin solution. Within 30 seconds of making mixture, a smear was made on microscope slide, air dried and examined under oil immersion (X 1000) of a light microscope. The percentage sperm viability was calculated using the number of live (white) sperm over total number of dead (pink/red) sperm cells.

\subsection{Protocol for tissue processing}

The tissues were fixed in 10\% formalin. They were processed (dehydrate in ascending grades of alcohol, cleared in xylene, and impregnated in molten paraffin wax) in Automatic tissue processor. The tissues were then embedded in paraffin wax using Embedding system (Leica EG 1160). They were thereafter sectioned with microtome at 4microns. The sections were then floated on water using water bath at $45^{\circ} \mathrm{C}$ and then picked on frosted end slide. The slides were fixed on hot plate for about thirty minutes and the sections stained by Heamatoxylin and Eosin method. 


\subsection{Statistical analysis}

The statistical analysis was carried out using Statistical package for Social Sciences (SPSS-17). Mean values of different treatments were compared using ANOVA (one-way). All data were expressed as mean \pm SD triplicate parallel measurements. Differences between means at $5 \%$ level $(\mathrm{p} \leq 0.05)$ were considered significant.

\section{Results and discussion}

\subsection{Acute toxicity test}

The acute toxicity effect of RBBM recorded no death for all the animals during phase 1 and phases 2 study as shown in Table 1. Effect of the drug on the body weight of the treated animals showed significant $(\mathrm{p}<0.5)$ change when compared with that of the control. An increase in body weight was recorded in the treated animals at day 7 , and these increases $(191.67 \pm 30.05)$ steadily as recorded on day 14 (Table 2). There changes in physical signs of toxicity across the phase 1 and phase 2 experimental groups (Table 3)

Table 1 Acute lethal effect of RBBM administered orally to the rats

\begin{tabular}{|l|c|c|c|}
\hline Groups & $\begin{array}{l}\text { Dose } \\
\text { (mg/kg.bw) }\end{array}$ & $\begin{array}{l}\text { No dead rats } \\
\text { after 24 hours }\end{array}$ & $\begin{array}{l}\text { Treated rats } \\
\text { after 24 hours }\end{array}$ \\
\hline Control & 0 & $0 / 3$ & $0 / 3$ \\
\hline Phase 1 & 10 & $0 / 3$ & $0 / 3$ \\
\hline & 100 & $0 / 3$ & $0 / 3$ \\
\hline & 1000 & $0 / 3$ & $0 / 3$ \\
\hline Phase 2 & 1600 & 1 & 1 \\
\hline & 2900 & 1 & 1 \\
\hline & 5000 & 1 & 1 \\
\hline Control & 0 & 1 & \\
\hline
\end{tabular}

Table 2 Effect of oral administration of RBBM on the body weights of rats during acute toxicity test

\begin{tabular}{|l|c|l|c|c|}
\hline Experiment & Dose(mg/kg.bw) & Day 0 (g) & Day 7 (g) & Day 14 (g) \\
\hline Control & 0 & $126.67 \pm 1.67$ & $136.67 \pm 6.67$ & $158.33 \pm 8.33$ \\
\hline Phase 1 & 10 & $136.67 \pm 6.67$ & $158.33 \pm 8.33$ & $183.33 \pm 8.33$ \\
\hline & 100 & $135.00 \pm 7.64$ & $151.67 \pm 13.02$ & $183.33 \pm 8.33$ \\
\hline & 1000 & $148.33 \pm 5.04$ & $160.00 \pm 20.82$ & $191.67 \pm 30.05$ \\
\hline Phase 2 & 1600 & $130.80 \pm 2.01$ & $150.23 \pm 2.12$ & $200.08 \pm 11.09$ \\
\hline & 2900 & $125.21 \pm 1.02$ & $130.70 \pm 5.09$ & $154.45 \pm 8.17$ \\
\hline & 5000 & $150.30 \pm 6.02$ & $175.65 \pm 4.02$ & $200.10 \pm 8.02$ \\
\hline
\end{tabular}


Table 3 Observation of physical signs in rats during acute toxicity study of RBBM

\begin{tabular}{|c|c|c|c|c|c|c|}
\hline \multirow{3}{*}{$\begin{array}{l}\text { Parameters } \\
\text { Dose }\end{array}$} & \multicolumn{6}{|c|}{ Experiment } \\
\hline & \multicolumn{3}{|c|}{ Phase I } & \multicolumn{3}{|c|}{ Phase II } \\
\hline & $\begin{array}{c}10 \\
\mathrm{mg} / \mathrm{kg} \cdot \mathrm{bw}\end{array}$ & $\begin{array}{c}100 \\
\text { mg/kg.bw }\end{array}$ & $\begin{array}{c}1000 \\
\text { mg/kg.bw }\end{array}$ & $\begin{array}{c}1600 \\
\text { mg/kg.bw }\end{array}$ & $\begin{array}{c}2900 \\
\mathrm{mg} / \mathrm{kg} \cdot \mathrm{bw}\end{array}$ & $\begin{array}{c}5000 \\
\mathrm{mg} / \mathrm{kg} . \mathrm{bw}\end{array}$ \\
\hline Lethargy & + & + & + & - & - & - \\
\hline Salivation & - & - & - & - & - & - \\
\hline Aggressiveness & - & - & + & + & + & + \\
\hline Food consumption & - & - & - & - & - & - \\
\hline Water consumption & - & - & - & - & - & - \\
\hline Sneezing & + & + & + & - & - & - \\
\hline Licking of paws & - & - & + & - & - & - \\
\hline Mortality & - & - & - & - & - & - \\
\hline
\end{tabular}

\subsection{Sub-acute toxicity test}

The effect of RBBM on the testes of albino Wistar rat is presented in Table 5 . There were no significant $(\mathrm{p}<0.05)$ changes observed in the weights of the testes of the control and RBBM treated animals, but a significant $(\mathrm{p}<0.05)$ reduction in testicular weight $(1.12 \pm 0.03)$ was observed in Group 1 animals that received $0.87 \mathrm{mg} / \mathrm{kg}$ b.w as compared to Group 2 $(1.18 \pm 0.37)$ that received $1.17 \mathrm{mg} / \mathrm{kg}$ b.w

Table 4 Physical signs observed in rats during sub-acute toxicity study of RBBM

\begin{tabular}{|l|c|c|c|}
\hline Experiment & $\begin{array}{l}\text { Dose } \\
\text { (mg/kg.bw) }\end{array}$ & $\begin{array}{l}\text { No of animals that } \\
\text { had nasal bleeding }\end{array}$ & $\begin{array}{l}\text { No of animals } \\
\text { that were paralyzed }\end{array}$ \\
\hline Group 1 & 0.87 & $0 / 5$ & $0 / 5$ \\
\hline Control & 0 & $0 / 5$ & $0 / 5$ \\
\hline Group 2 & 1.73 & $2 / 5$ & $0 / 5$ \\
\hline
\end{tabular}

Table 5 Effect of RBBM on organ (testes) weight of male albino Wistar rats

\begin{tabular}{|c|c|c|c|}
\hline Parameter & Group 1 & Group 2 & Control \\
\hline Weight (testes) & $1.12 \pm 0.03^{*}$ & $1.18 \pm 0.37$ & 0.09 \\
\hline \multicolumn{4}{|c|}{ Asterisk $\left({ }^{*}\right)$ value are significant different at $\mathrm{p}<0.05$} \\
\hline
\end{tabular}

\subsection{Sperm parameters}

Table 6 summarized the effects of the RBBM on sperm parameters. Sperm count and sperm motility increases significantly $(\mathrm{p}<0.05)$ as seen in group 1 and group 2 as compared to the control. Also, there was decrease in the number of multiple tail sperm as the dose of RBBM increases in group 1 and group 2 respectively. 
Table 6 Effect of different test doses of RBBM on sperm parameters of male albino Wistar rats

\begin{tabular}{|l|c|c|c|}
\hline Parameters & $\begin{array}{l}\text { Group 1 } \\
\mathbf{( 0 . 8 6 6 ~} \mathbf{~ m g} / \mathbf{k g . b w})\end{array}$ & $\begin{array}{l}\text { Group 2 } \\
\mathbf{( 1 . 7 3 4} \mathbf{~ m g} / \mathbf{k g . b w})\end{array}$ & $\begin{array}{l}\text { Control } \\
\mathbf{0 ~} \mathbf{~ m g} / \mathbf{k g . b w}\end{array}$ \\
\hline Sperm motility & $93.20 \pm 0.04^{*}$ & $92.00 \pm 2.12$ & $91.75 \pm 1.10$ \\
\hline Sperm count & $15.64 \pm 0.03^{*}$ & $14.98 \pm 0.44$ & $14.85 \pm 0.37$ \\
\hline Sperm viability (life/death ratio) & $95.40 \pm 0.51$ & $93.50 \pm 1.76$ & $94.50 \pm 1.04$ \\
\hline Headless & $2.60 \pm 0.24$ & $3.25 \pm 0.48$ & $3.25 \pm 0.25$ \\
\hline Multiple tail & $3.20 \pm 0.37$ & $3.00 \pm 0.41$ & $3.50 \pm 0.65$ \\
\hline Curved tail & $3.20 \pm 0.37$ & $3.25 \pm 0.25$ & 0.48 \\
\hline
\end{tabular}

Asterisk $(*)$ value are significant different at $\mathrm{p}<0.05$

\subsection{Histopathological study}

A cross section of the normal testicular tissue (Fig. 1A) showed moderate maturation of the spermatids, developing from the spermatogonia and spermatocytes. The leydigs and sertolis cells appear normal. The photomicrograph of group one animal testes (Fig. 1B) showed optimal maturation of spermatids as evidenced by abundance of spermatids in the lumen of the tubules. The leydigs and sertolis cells have normal appearance. The photomicrograph of group 2 animal testes (Fig. 1C) showed that the spermatids are in different stages of maturation from spermatogonia and spermatocytes. The leydigs and sertolis cells look normal.
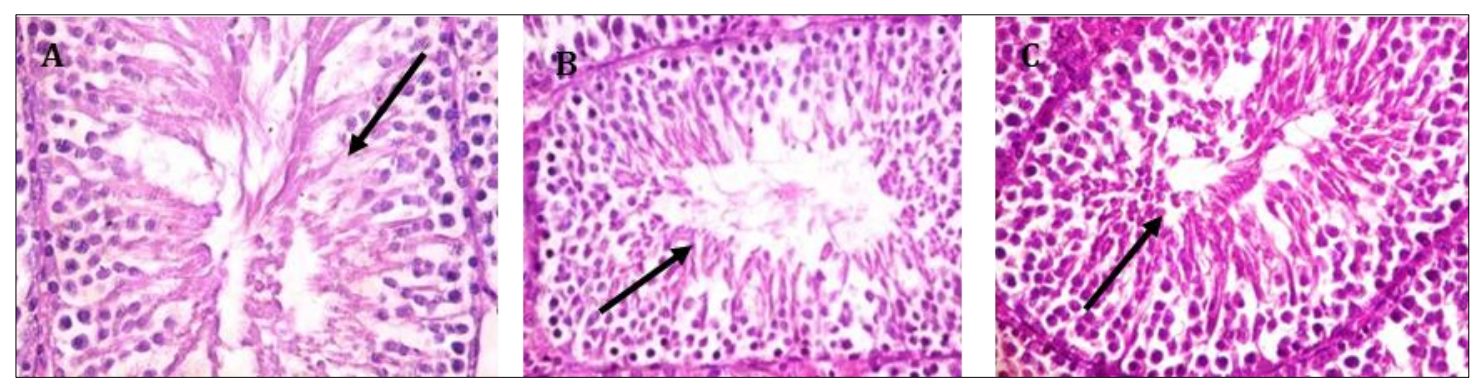

Figure 1 (A-C) Photomicrograph of testicular tissues. (A) Control group, treated with distilled water show moderate maturation of spermatids as evidenced by moderate presence of spermatids in the lumen of the tubules. The spermatids are in different stages of maturation from spermatogonia, spermatocytes and spermatids. The leydigs and sertolis cells look normal; (B) group 1 animals, treated with $0.87 \mathrm{mg} / \mathrm{kg}$.bw RBBM show optimal maturation of spermatids as evidenced by abundant presence of spermatids in the lumen of the tubules. The spermatids are in different stages of maturation from spermatogonia, spermatocytes and spermatids. The leydigs and sertolis cells look normalan (C) group 2 animals treated with $1.17 \mathrm{mg} / \mathrm{kg}$.bw RBBM show moderate maturation of spermatids as evidenced by moderate presence of spermatids in the lumen of the tubules. The spermatids are in different stages of maturation from spermatogonia, spermatocytes and spermatids. The leydigs and sertolis cells look normal.

\section{Discussion}

Male reproductive system is very sensitive to various environmental factors such as lifestyle, drugs, radiation and pollution among others and exposure to these conditions could result into congenital abnormalities in infants and functional alterations in adults $[10,11)$. Several natural and synthetic products are reported to target the testes to interfere with either its hormonal function or spermatogenesis or both [12]. The acute lethal study of RBBM on the rats did not result into any morbidity as all rats survived beyond 24 hours of examination. Also, no death was recorded in the experimental rats after two weeks. Thus, the acute median lethal dose $\left(\mathrm{LD}_{50}\right)$ of RBBM was greater than 5000 $\mathrm{mg} / \mathrm{kg}$.bw. Hence, this polyherbal mixture is classified to be non-toxic using Klaasen indicator [13]. The result showed that RBBM herb could be safely administered up to the dose of $5000 \mathrm{mg} / \mathrm{kg}$.bw/day. The major signs of toxicity noticed within 24 hours included lethargy among the phase 1 group, aggressiveness that became increasingly pronounced as the dose increased from $1600 \mathrm{mg} / \mathrm{kg}$.bw to $5000 \mathrm{mg} / \mathrm{kg} . \mathrm{bw}$. Furthermore, the dose dependent difference in weight was not significant $(\mathrm{p}<0.05)$ when compared to the control. 
In the sub-acute toxicity study, nasal bleeding was observed in two of the animals that were administered a dose of 1.73 $\mathrm{mg} / \mathrm{kg}$.bw. These clinical signs suggest that $1.73 \mathrm{mg} / \mathrm{kg} /$ day (equivalent of 2 capsules per day) may not be safe to prescription by the healthcare providers. The andrological results show that treatment of rats for 28 days with Ruzu bitters caused significant $(\mathrm{p}<0.05)$ difference in sperm motility compared to the control. Ruzu bitters caused no significant difference both in viability and in morphological abnormality of sperm cells in the treated rats. The histopathology of the testes of subjects did not show any visible macroscopic transformation.

\section{Conclusion}

The RBBM herb is relatively safe as demonstrated in the results herein. The study observed that RBBM is not toxic to seminal parameters analyzed in this study. Consumers of RBBM should not rule out completely the possibility of chronic toxicity developing with the continual use of RBBM.

\section{Compliance with ethical standards}

\section{Acknowledgments}

We wish to express our appreciation to the Department of biochemistry, Babcock University for providing the Laboratory space used to carry out the analysis for this study.

\section{Disclosure of conflict of interest}

The authors declare that they have no known competing financial interests or personal relationships that could have appeared to influence the work reported in this paper.

\section{Statement of ethical approval}

This research is in full compliance with ethical standards and was approved by Babcock University Health Research Ethics Committee.

\section{References}

[1] Falodun A, Imieje V. Herbal Medicine in Nigeria: Holistic Overview Nigerian Journal of Science and Environment. 2013; 12(1): 1-13.

[2] Ogbonna SO, Mbaka GO, Anyka EN, Emordi JE, Nwakakwa N. An evaluation of acute and subchronic toxicties of a Nigerian polyherbal tea remedy. Parkistan Journal of Nutrition. 2011; 10: 1022 - 1028.

[3] Ansari J, Inamda N. The promise of traditional medicine. International Journal of Pharmacology. 2010; 6: 808812.

[4] World Health Organization. Legal status of traditional medicines and complementary medicines, A worldwide review World health. 2020.

[5] Enuh H, Oragwu C, Okeke C, Elu E, Orisakwe O. Semen Abnormality and Nigerian Herbal Remedies: A Preliminary Investigation. The International Journal of Toxicology. 2012; 8(2).

[6] Lorke D. A new approach to practical acute toxicity testing. Archive of Toxicology. 1983; 54: $275-287$.

[7] Otimenyin SO, Kolawole JA, Nwosu M. Pharmacological basis for the continual use of the root of sennasiamea in traditional medicine international. Journal of Pharmacology and biological sciences. 2010; 1(3): 1- 9.

[8] World Health Organization (WHO). Laboratory Manual for Examination of Human Semen and Semen-Cervical Mucus Interaction, 2nd ed. London: Cambridge University Press. 1987; 1-10.

[9] Morakinyo AO, Achema PU, Adegoke OA. Effect of Zingiber Officinale (Ginger) on Sodium Arsenite-induced Reproductive Toxicity in Male Rats. African Journal Biomedical Research. 2010; 13(1): 39-45.

[10] Ogbonna SO, Mbaka GO, Nkemehule FE, Emordi JE, Okpagu NC, Ota DA. Acute and Subchronic Evaluation of Aqueous Extrat of Nebouldia laevis (ignoniaceae) and Nauclea latifolia (Rubiaceae) Roots used singly or in Combination in Nigeria Traditional Medicines. British Journal of Pharmacology and Toxicology. 2014; 5(1): 5562. 
[11] Saradha B, Mathur PP. Effect of environmental contaminants on male reproduction. Environmental Toxicology and Pharmacology. 2006; 21(1): 34-41.

[12] Shajeela PS, Mohan VR, Louis JL, Tresina SP. Antifertility activity of ethanol extract of Dioscorea esculenta (L.) Schott on male albino rats. International Journal of Pharmacological Technology Research. 2011; 3(2): 946-954.

[13] Klaasen CD, Amdur MO, Doull J. Casarett and Doull's Toxicology: The Basic Science of Poison. 8th ed. New York: Mc Graw Hill. 1995; 13-33. 